\title{
Introducing COPD Research and Practice
}

CrossMark

\author{
Mario Cazzola
}

Chronic obstructive pulmonary disease (COPD) is now the fourth leading cause of death globally, and the World Health Organization (WHO) has predicted that it will become the third most common cause of death in the world by 2030 [1]. In developed countries, current information estimates a prevalence of $8 \%$ to $10 \%$ among adults 40 years of age and older, whereas in developing countries, prevalence varies significantly among countries and is difficult to quote [2].

It is estimated that more than 210 million people have the disease worldwide [3]. Concerning a large number of subjects, COPD generates important health and social costs. However, although COPD is one of the most common chronic diseases and has a high health and social impact, it is still poorly recognized among the general public and also clinicians. Consequently, there is a major and urgent need to better understand this complex disease.

Since I started to get interested in this disease, more than 40 years ago, major progress has been made in the identification, pathogenesis, assessment and treatment of COPD. Nonetheless, many important questions remain unanswered. Peter J. Barnes [4] has properly and authoritatively emphasized that we still do not understand why only a minority of smokers develop airway obstruction, nor the complex interplay between different risk factors in addition to smoking and biomass smoke exposure. Moreover, we do not realize how the underlying inflammatory process is linked to pathophysiology and disease progression and the reason why inflammation and disease progression persist even after smoking cessation.

COPD is a heterogeneous disease and can be classified into different "phenotypes" [5]. For many years, clinicians have noted two very different subgroups of patients in COPD, those with chronic bronchitis and those with emphysema [6]. Recently, the Evaluation of COPD Longitudinally to Identify Predictive Surrogate Endpoints (ECLIPSE) study has helped improve the characterization of other subsets of patients, including the

Correspondence: mario.cazzola@uniroma2.it

Division of Respiratory Medicine, Department of Internal Medicine, University Hospital "Tor Vergata", Rome, Italy frequent exacerbator versus the infrequent exacerbator and the patient with persistent systemic inflammation versus the patient without systemic inflammation [7].

Rennard and Vestbo suggested that COPD should qualify for orphan status for two reasons: the condition is heterogeneous; and the various phenotypes of COPD likely represent specific conditions that are relatively rare [8]. This is a provocation, but it had the merit of having emphasized the need for a more individualized therapeutic approach. The different phenotypes may respond differently to different treatments, but this is poorly understood. The interrelationships between all aspects of the disease (e.g. genetic, biological, environmental, clinical, social) will surely offer new possibilities to converge towards a new focus on COPD management that aims at personalized treatment, challenging and overcoming the classical concepts of the disease [9]. Unfortunately this approach, although extremely appealing, is still in its infancy.

In any case, although long-acting bronchodilators have proved to be the most effective therapies so far available [10], there are still fundamental questions regarding their use that require clarification to optimise utilisation of these drugs [11]. We do not know yet if it is appropriate to treat all COPD patients with long-acting bronchodilators, it is better to start with a $\beta_{2}$-agonist or with an anti-muscarinic agent, it is useful to use a bronchodilator with a rapid onset of action, once- or twice-daily dosing is preferable. We also do not know yet when we can add a second bronchodilator with a different mechanism of action and when we must add an inhaled corticosteroid. Moreover, we still do not have treatments that suppress the underlying inflammatory process to prevent disease progression and exacerbations [4].

Since COPD patients are at increased risk for comorbidities such as cardiovascular disease, non-psychotic mental disorders, including depressive disorders, diabetes mellitus, osteoporosis, malignant pulmonary neoplasms, skeletal muscle wasting and cachexia [12], in these last years, we have realised that there is a strong need to look beyond the lungs in treating patients with COPD [13]. However, the two different views relating 
the observed associations between COPD and its manifestations and comorbid diseases have important therapeutic consequences [13]. The most likely link between COPD and the extrapulmonary conditions is the spillover of inflammatory mediators from the lung [12], but it has also been suggested that COPD could be considered as part of a 'chronic systemic inflammatory syndrome' [14]. In the spillover theory, the aim of therapy is primarily centred in the lungs [13]. A reduction in local inflammation might influence systemic inflammation and have beneficial effects on the systemic effects of COPD. In the 'chronic systemic' inflammatory state with multiple organ impairment, the centre of therapy should be shifted to the systemic inflammatory state [13]. Nonetheless, we still do not know whether the successful treatment of the comorbid diseases associated with COPD also positively influences the course of the lung disease.

The recent American Thoracic Society/European Respiratory Society research statement has highlighted the many, different types of research that leading clinicians, researchers and patient advocates believe will have the greatest impact on patient-centred outcomes [15]. The reading of this statement makes possible to realize how important an exhaustive research on COPD is urgent and absolutely necessary.

It is generally believed that publications represent the central part of a research process. The results of a research study, even when they are negative, are useless if they are not disclosed. If data is not disseminated to the scientific community, they cannot help us to expand our knowledge. This is something that we cannot accept, given the burden of COPD and a thousand unanswered questions that we still have.

For this reason, I accepted the challenge of founding a new journal focused on all aspects of COPD. It is not by chance that we called it COPD Research and Practice. COPD Research and Practice aims to publish basic and clinical research and cutting edge reviews related to this disease. In particular, the journal aims to facilitate discussion and dissemination of knowledge to help translate new ideas from bench to bedside by encouraging international and interdisciplinary collaboration. It is an open access journal, which means that all articles published by COPD Research and Practice are made freely and permanently accessible online immediately upon publication, without subscription charges or registration barriers.

I recognize that our programme is ambitious, but I am confident that our aims will be achieved thanks to the help of a very valuable Editorial Board. Experts with strongly recognized international reputations from several different countries have generously accepted my invitation to be part of the Editorial Board and are supporting me in the difficult task of helping the journal take its first steps. Obviously, I cannot forget the fundamental support that I have received from BioMed Central.

We welcome you to support COPD Research and Practice.

Received: 14 July 2015 Accepted: 14 July 2015

Published online: 19 August 2015

\section{References}

1. World Health Organization. World Health Statistics. 2008. Available from http://www.who.int/whosis/whostat/2008/en/index.html.

2. Diaz-Guzman E, Mannino DM. Epidemiology and prevalence of chronic obstructive pulmonary disease. Clin Chest Med. 2014;35:7-16.

3. Bousquet J, Kiley J, Bateman ED, Viegi G, Cruz AA, Khaltaev N, et al. Prioritised research agenda for prevention and control of chronic respiratory diseases. Eur Respir J. 2010;36:995-1001.

4. Barnes PJ. Preface. Chronic obstructive pulmonary disease. Clin Chest Med 2014;35: xiii.

5. Han MK, Agusti A, Calverley P, Celli B, Criner G, Curtis JL, et al. Chronic obstructive pulmonary disease phenotypes: the future of COPD. Am J Respir Crit Care Med. 2010;182:598-604.

6. Burrows B, Fletcher CM, Heard BE, Jones NL, Wootliff JS. The emphysematous and bronchial types of chronic airways obstruction. A clinicopathological study of patients in London and Chicago. Lancet. 1966;1:830-5.

7. Vestbo J, Augusti A, Wouters EFM, Bakke P, Calverley P, Celli B, et al. Should we view chronic obstructive pulmonary disease differently after ECLIPSE? A clinical perspective from the study team. Am J Respir Crit Care Med. 2014;189:1022-30.

8. Rennard SI, Vestbo J. The many "small COPDs": COPD should be an orphan disease. Chest. 2008;134:623-7.

9. Lopez-Campos JL, Bustamante V, Muñoz X, Barreiro E. Moving towards patient-centered medicine for COPD management: multidimensional approaches versus phenotype-based medicine-a critical view. COPD. 2014;11:591-602

10. Cazzola M, Matera MG. Bronchodilators: current and future. Clin Chest Med. 2014;35:191-201

11. Cazzola M, Page C. Long-acting bronchodilators in COPD: where are we now and where are we going? Breathe. 2014;10:110-20.

12. Barnes PJ. Chronic obstructive pulmonary disease: effects beyond the lungs. PLoS Med. 2010;7, e1000220.

13. Matera MG, Calzetta L, Rinaldi B, Cazzola M. Treatment of COPD: moving beyond the lungs. Curr Opin Pharmacol. 2012;12:315-22.

14. Nussbaumer-Ochsner Y, Rabe KF. Systemic manifestations of COPD. Chest. 2011;139:165-17

15. Celli B, Decramer M, Wedzicha J, Wilson K, Agusti A, Criner G, et al. An official American Thoracic Society/European Respiratory Society statement: research questions in COPD. Eur Respir J. 2015;45:879-905.

\section{Submit your next manuscript to BioMed Central and take full advantage of:}

- Convenient online submission

- Thorough peer review

- No space constraints or color figure charges

- Immediate publication on acceptance

- Inclusion in PubMed, CAS, Scopus and Google Scholar

- Research which is freely available for redistribution 